\title{
EXPERIMENTAL INVESTIGATION OF BALL BEARING LUBRICATION CONDITIONS BY SHOCK PULSE METHOD
}

\author{
R. K. Gupta ${ }^{1}$, V. Rastogi ${ }^{1}$, R. C. Singh ${ }^{1}$, N. Tandon ${ }^{2}$ \\ ${ }^{1}$ Delhi Technological University, Delhi - 110042 (INDIA) \\ ${ }^{2}$ Indian Institute of Technology, Delhi, Delhi - 110016 (INDIA)
}

\begin{abstract}
Lubricant (grease) is a vital requirement of ball bearing system. Grease not only protects ball bearing from wear and tear but performs various other functions that are essential for proper functioning of ball bearings. The lubricant (grease) under different conditions attains different properties which in turn affect the performance of the ball bearings. The effect of the condition of the lubricants on the performance of the ball bearings is well documented. the work reports about the investigation of ball bearing using shock pulse method by using two different instruments (Tester T2000 Model and Shock Pulse Meter 43A) of different operating conditions of ball bearing the condition such as used the quantity of grease as different percentage $(0 \%, 25 \%$, $50 \%, 75 \%, 100 \%$ ) and bad quality grease (burn grease) at different rpm at a fixed load (10kg) and compare the normalized shock pulse value $(\mathrm{dB})$ at different operating conditions. This method uses a piezo-electric accelerometer superimposed electrically as well as mechanically to about $32 \mathrm{kHz}$ of resonant frequency. The result will help in bearing related to quantity as well as quality condition based maintenance choosing the optimum conditions for detecting the lubricant problem in ball bearing.
\end{abstract}

Keywords: Ball bearing, lubrication, shock pulse, grease.

*Corresponding author: Ratnesh Kumar Gupta (rgiitdelhi@gmail.com)

\section{INTRODUCTION}

Ball bearings are considered to be most critical components of household applications to heavy machineries like locomotives and turbines. Grease is the mostly used lubricant for ball bearings mainly because they are comparatively convenient to handle and needs the easiest of sealing devices. Greases are applied in areas where a continuous supply of oil cannot be done, like open bearing or gears. Factor like type of grease, in fact depends upon operating temperatures, oxidation stability, water resistance, etc. The other factors include characteristics like viscosity and consistency. There are many routes to check and measure the intensity of lubrication in ball bearing problems. Vibration analysis, acoustic emission, and shock pulse are just a few of the methods used today, to detect the ball bearing lubrication condition measurement. Most lubrication practices are often performed on a time basis, which can result in over lubrication causing premature bearing failure. For the monitoring of the ball bearing lubrication condition have been used the most affective measurement method like shock pulse [1]. In industrial application, a critical role is played by rolling element bearings. There may be significant economic losses due to unexpected bearing failures. An effective way to prevent the bearing failures is condition monitoring. For bearing condition monitoring, Tandon and Choudhary have set up a detailed review in the area of vibration and acoustic methods [2]. As a quantitative method for detecting the defects of rolling element bearings, the shock pulse method (SPM) is widely accepted. In the SPM, 
the maximum normalized shock value is used as a measure of bearing condition [3]. By this method, a single value indicating the bearing condition is achieved and there is no need for elaborate data interpretation as required in some other methods (e.g. traditional spectral analysis, cepstrum analysis [4], cyclic statistics [5], empirical mode decomposition (EMD) [6], wavelet transform [7], etc). However, the shock value in the SPM may be mistakenly estimated by direct demodulation. To overcome this deficiency, wavelet transform which is based on lifting scheme is applied to pre-process the vibration signals of rolling bearing [8].

\section{$\underline{\text { Shock pulse measurement }}$}

The Shock Pulse Method (SPM) [9] was developed by SPM Instrument AB, Sweden in 1970s. It is based on the fact that an impulse of vibration is generated when a ball or roller in the bearing touches with a scratched area of raceway or with debris. Sign of bearing condition is given by maximum normalized shock value $(\mathrm{dB})$.

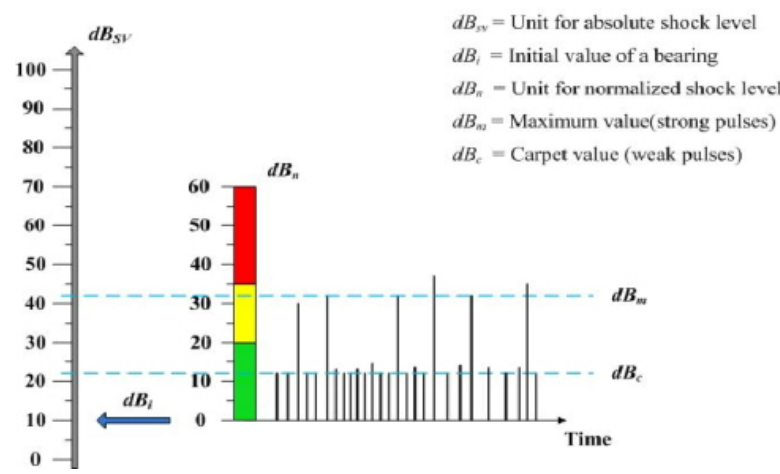

Fig. 1 Various values of SPM and their range [9].

It is given by $\mathrm{dB}=$ $20 \log 2000$ SVND0.6 where $\mathrm{N}$ is the bearing rotational speed, and $\mathrm{D}$ represents the inner diameter of the bearing. SV denotes the shock value, which is computed by demodulation of signals of bearing vibration. The bearing operation conditions can be approximated with $\mathrm{dB}$ value as [10]. Table 1 represents the various values of $\mathrm{dB}$ for different bearing conditions.
Table 1.

\begin{tabular}{cl}
\hline $\begin{array}{l}\text { Normalized shock } \\
\text { pulse value }(d B)\end{array}$ & Bearing condition \\
\hline $0-20$ & Good \\
\hline $20-35$ & $\begin{array}{l}\text { Caution (Bearing to be } \\
\text { damaged) }\end{array}$ \\
\hline$>35$ & Bearing damaged \\
\hline
\end{tabular}

The limits of the three condition regions were set empirically through the testing of bearings under variable operating conditions in the 1970s. Among all three regions, SPM has been most successfully established to get reliable identification of the working conditions of rolling element bearings and lubrication conditions. Moreover, these limits have been widely accepted in industries because of their successful application Figure 2 shows the various types of lubrication failure shock pulse range. (a)

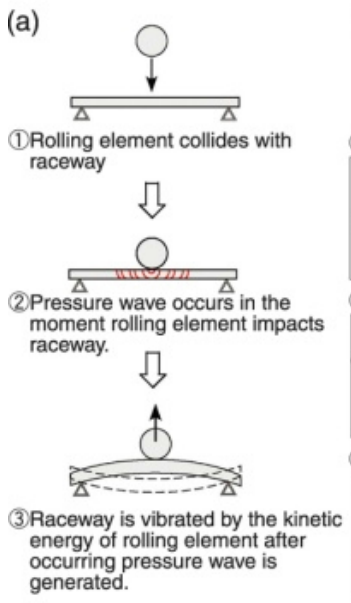

(b)
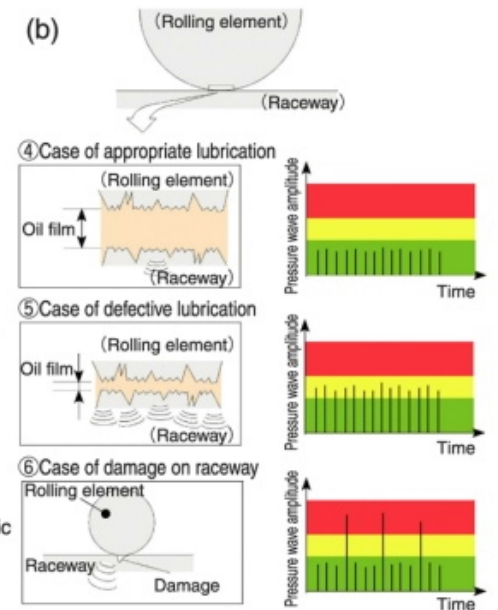

Fig. 2 Various type of lubrication failure shock pulse range [11].

\section{REQUIRED INSTRUMENTS AND MATERIALS}

The experimentation has been performed Shock Pulse Meter T-2000 tester with accelerometer and Shock Pulse Meter 43A instruments available in noise \& vibration lab in Industrial Tribology and Maintenance Centre at Indian Institute of Technology, Delhi. The detailed information regarding the aforesaid instruments are as under: 
Shock Pulse Meter $T-2000$ tester with accelerometer

The $T-2000$ is switched on by pressing any of the five function keys. Power down function is automatic and happens approx 30 seconds after a function key is pressed. If the instruments fails to power down within one minute, press the unmarked master reset key. The TNC connector $\operatorname{SPM}(9)$ is used FPR shock pulse transducers (hand held probe, transducer with quick connector or measuring cable connecting to a measuring terminal).

The BNC connector VI $\mathrm{B}(11)$ is used for the vibration transducer. SPM and VI B transducer may be connected simultaneously. The key SPM /VI B switches between shock pulse meter and vibration measuring mode. The connector TAC (10) receives both the tachometer probe and the earphone. The tachometer mode is active while the tachometer probe is connected the ear phone mode is active while the earphone is connected.

\section{Memory}

When the $T-2000$ powers down or is switch other measuring mode the following reading is remembered.

-The last shock pulse reading $(\mathrm{dBm}, \mathrm{dBc}$ and $d B i$ setting)

-The last vibration reading (vibration severity and machine class setting)

-The last rpm reading

In addition, changing instruments settings after pressing the key will not change the last reading.

\section{$\underline{\text { Shock pulse measurements }}$}

Normalized shock pulse readings show the bearing condition. These require the input of the bearings initial value $d B i$ the measuring unit is $d B n$ (normalized shock value). The $T-2000$ accepts $d B i$ value from -9 to + 40 . Un-normalized reading shows the magnitude of the shock signal in absolute terms. The measuring unit is $d B s v$ (decibel shock value). The $d B i$ is set to (two, hyphen which is the setting below -9 . Setting the initial $d B i$ - the initial value $d B i$ canbe changed in three different ways, illustrated with direct change of the $\mathrm{dBi}$, setting RPM and shaft diameter. Measure parameter:-carpet value of shock pulse $(d B c)$, maximum value of shock pulse $(\mathrm{dBm})$.

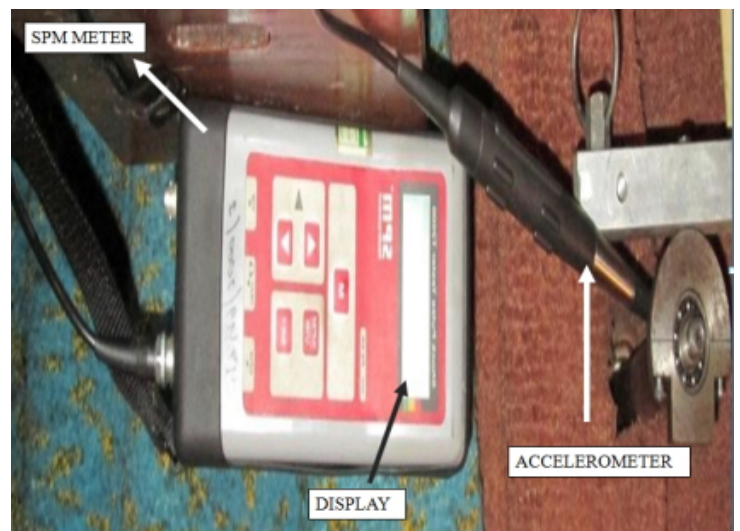

Fig. 3 Shock Pulse Meter $T-2000$ with accelerometer.

\section{$\underline{\text { Shock Pulse Meter (43A) }}$}

Shock pulse measurements begins at the lowest reference level, the thumb wheel is turned clockwise to $d B n$. The shock pulse meter registers now the large number of minor shock pulse which occurs in every rotating ball and roller bearing. Their minor shock pulse constitutes the noise carpet of the bearing. These are generated in very rapid sequence. The sound pulse from the instruments follows each other so closely that they form an even continuous tone.

When the bell of the strength indicator is placed higher, fewer people are able to make it ring. When the thumb wheel on the shock pulse meter is turned further counter clockwise, the number of sound pulses decreases. The range $\mathrm{b} / \mathrm{w}$ noise carpet and peak value is of minor interest for shock pulse measurements. By turning the thumb wheel from the starting point $(0 d B n)$ counter clockwise, it tries to find the level where the sound just changes from a 
continuous tone to an intermittent tone. This change makes the upper limit of the noise carpet. The corresponding shock pulse value $d B c$ (decibel carpet value) is the reading of the instruments dial.

The carpet value $d B c$ is a measure of the normal surface roughness which exits even in perfect bearing. A bearing is of good operating condition normally has a carpet value below 10 $d B n$. This shock pulse meter consists of transducer with probe type 10777 max 60 $d B s v$ (made in Sweden) and a microphone.

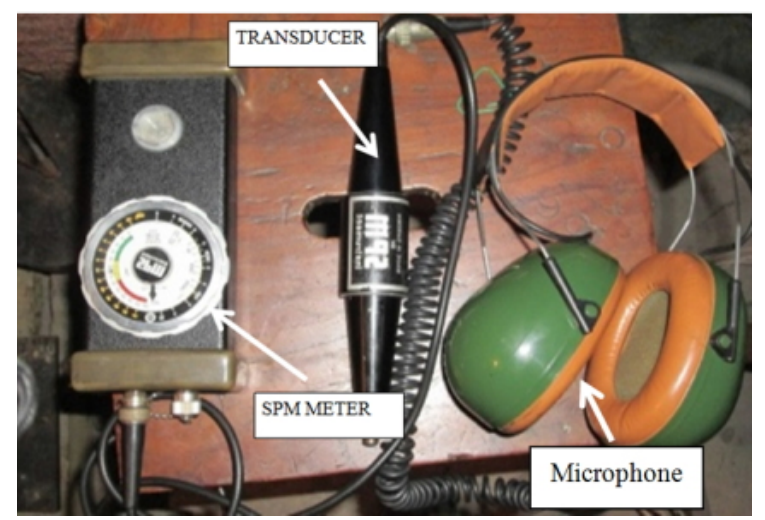

Fig. 4 shock pulse meter $43 \mathrm{~A}$ with transducer and microphone.

\section{$\underline{\text { SKF ball bearing }}$}

For calculating the data at different operation ball bearing conditions, skf ball bearing 6002 was used. Figure 5 shows the photographic view of the ball bearing with fresh and burnt grease. The details of the same are as under: skf ball bearing 6002 new without lubrication (both end opened and dry), Bore dia - $15 \mathrm{~mm}$;Outer dia (D) - $32 \mathrm{~mm}$; Thickness $(B)$

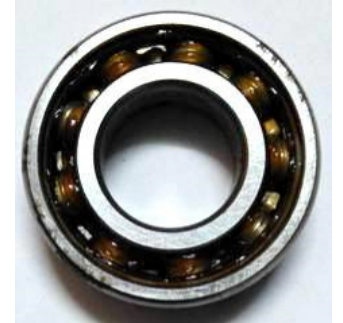

(a)

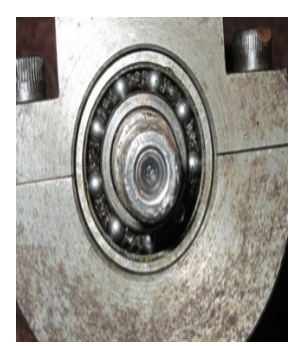

(b)
Fig. 5 SKF - 6002 ball bearing (a) fresh grease and (b) burnt grease.

\section{Grease}

Li based grease, fresh and burnt type grease, has been used for the experimentation. Figure 6 shows the pictorial view of fresh and burnt grease.

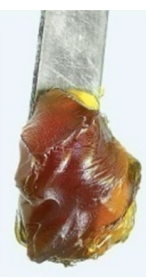

(a)

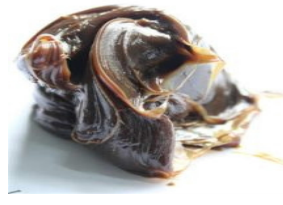

(b)
Fig. 6 Li based (a) fresh and (b) burnt grease.

\section{EXPERIMENTAL SETUP}

Experimentation was performed with different percentage values of fresh grease and burnt grease used in the ball bearing on both Shock Pulse (SP) Meter $T-2000$ and 43A. At first, the data was collected with the help of SP meter model no. $T-2000$ and it was further followed by verifying it with SP meter $43 A$ along with microphone where human skill also plays an important role. Figures 7 and 8 represent the schematic and pictorial views of the experimental set-up. 


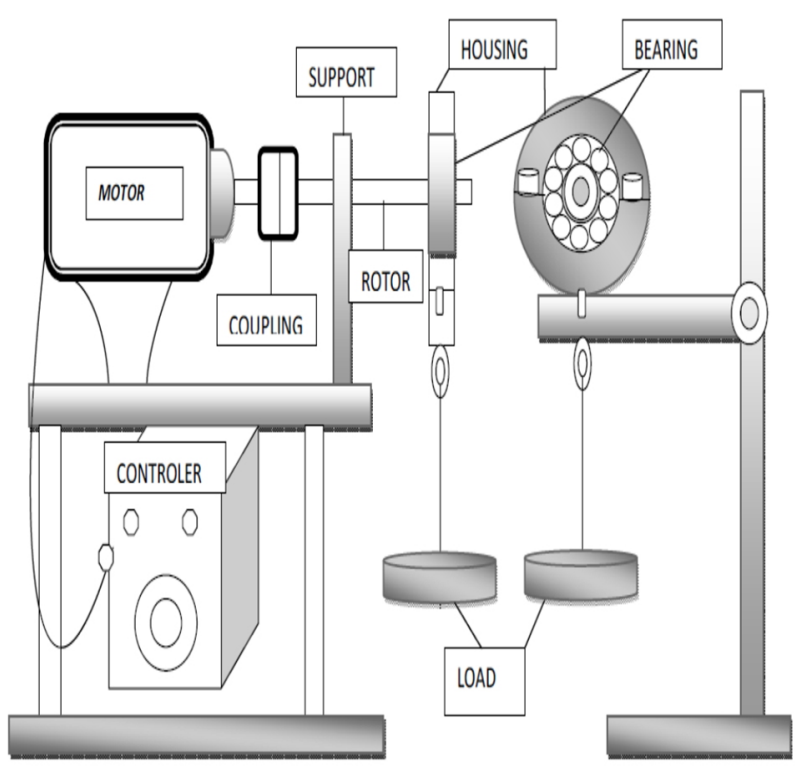

Fig. 7 Experimental set-up for testing of ball bearing with SPM.

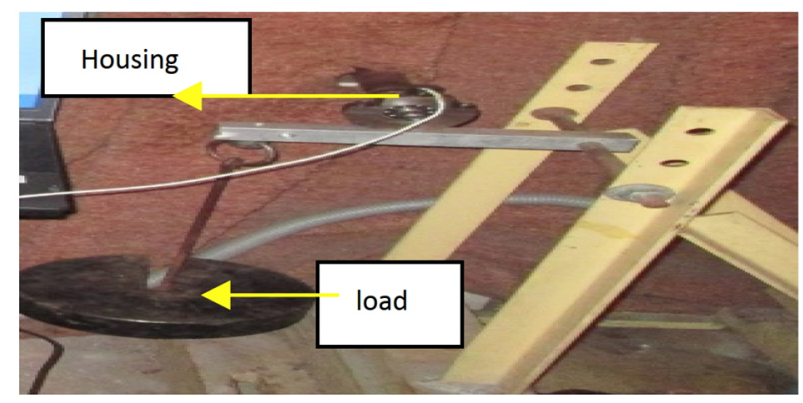

Fig. 8 Test rig set-up with loading system.

\section{EXPERIMENTATION}

The test samples have been prepared for the experiment. At first, the quantity of the fresh grease was measured with the help of ball bearing formula which is given below Quantity of grease $(\mathrm{gm})=.005 \times \mathrm{D} \times \mathrm{B}$, DOuter dia ( $\mathrm{mm})$, B-Thickness of bearing (mm).

In this experiment:

Outer diameter $=32 \mathrm{~mm}$, Thickness of bearing $=9 \mathrm{~mm}$

Qty of grease $=.005 \times 32 \times 9=1.44$ gm. $=$ $1440 \mathrm{mg}$.
Table 2.

\begin{tabular}{lllll}
\hline $\begin{array}{l}\text { S. } \\
\text { No. Quantity } \\
\text { of grease }\end{array}$ & $\begin{array}{l}\text { Qty (m) Load } \\
\text { applied } \\
\text { (kg) }\end{array}$ & rpm of Bearing \\
\hline 1. & $0 \%$ & $\begin{array}{l}\text { Dry } \\
\text { running }\end{array}$ & 10 & $\begin{array}{l}300,500,1000, \\
1200,1500\end{array}$ \\
\hline 2. & $25 \%$ & $360 \mathrm{mg}$ & 10 & $\begin{array}{l}300,500,1000, \\
1200,1500\end{array}$ \\
\hline 3. & $50 \%$ & $720 \mathrm{mg}$ & 10 & $\begin{array}{l}300,500,1000, \\
1200,1500\end{array}$ \\
\hline 4. & $75 \%$ & $1080 \mathrm{mg}$ & 10 & $\begin{array}{l}300,500,1000, \\
1200,1500\end{array}$ \\
\hline 5. & $100 \%$ & $1440 \mathrm{mg}$ & 10 & $\begin{array}{l}300,500,1000, \\
1200,1500\end{array}$ \\
\hline & $100 \%$ & & 10 & $300,500,1000$, \\
6. & $\begin{array}{l}\text { (Burnt } \\
\text { grease) }\end{array}$ & $1440 \mathrm{mg}$ & 1000,1500 \\
\hline
\end{tabular}

Table 2 represents the different quantities of the grease taken for the experimentation. Then, a load of $10 \mathrm{~kg}$ was applied on the running state of the bearing. The rpm of the ball bearing were kept at $300,500,1000,1200$ and 1500

respectively. The rpm of the bearing was obtained with the SP meter instrument and consequently the speed of the rotor shaft was confirmed with the help of laser type speedometer.

\section{EXPERIMENTAL RESULTS}

Table 3 and Table 4 show the experimental results for each type of test samples, as discussed in Table 2. These tables also include the shock pulse value $d B c$ (carpet value) and $d B m$ (maximum value). Figure 9 and 10 show the relative graphs of effect of $d B c$ and $d B m$ on Qty of grease and speed (rpm). The load was fixed at $10 \mathrm{~kg}$ for both the cases.

Effect of Shock pulse carpet value $(d B c)$ on Qty of grease and Speed (rpm)

Shock pulse carpet value $(d B c)$ was taken from the SP meter $T-2000$ at different samples. 
Table 3.

\begin{tabular}{lccccc}
\hline $\begin{array}{l}\text { Speed } \\
(\mathrm{rpm})\end{array}$ & 300 & 500 & 1000 & 1200 & 1500 \\
\hline $\begin{array}{l}\text { Grease } \\
0 \%\end{array}$ & 17 & 19 & 17 & 18 & 19 \\
\hline $\begin{array}{l}\text { Grease } \\
25 \%\end{array}$ & 16 & 16 & 15.5 & 15 & 15 \\
\hline $\begin{array}{l}\text { Grease } \\
50 \%\end{array}$ & 10 & 11 & 8 & 9 & 9 \\
\hline $\begin{array}{l}\text { Grease } \\
75 \%\end{array}$ & 9 & 7.5 & 7.5 & 8 & 7 \\
\hline $\begin{array}{l}\text { Grease } \\
100 \%\end{array}$ & 8 & 7 & 7 & 7.5 & 7 \\
\hline
\end{tabular}

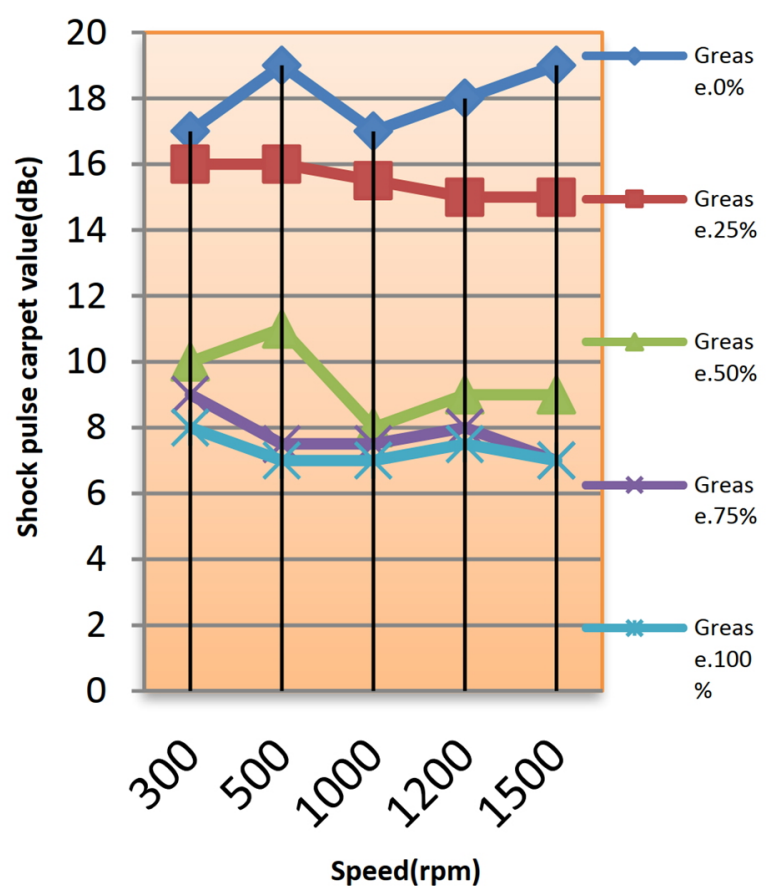

Fig. 10 Effect of qty of grease on shock pulse carpet value $(\mathrm{dBc})$ and rpm.

Shock pulse maximum value $(\mathrm{dBm})$

Shock pulse maximum value $(\mathrm{dBm})$ was taken from the SP meter $T-2000$ at different samples.
Table 4.

\begin{tabular}{lccccc}
\hline $\begin{array}{l}\text { Speed } \\
\text { (rpm) }\end{array}$ & 300 & 500 & 1000 & 1200 & 1500 \\
\hline $\begin{array}{l}\text { Grease } \\
0 \%\end{array}$ & 35 & 35 & 36 & 35 & 35 \\
\hline $\begin{array}{l}\text { Grease } \\
25 \%\end{array}$ & 30 & 34 & 33.5 & 31 & 32 \\
\hline $\begin{array}{l}\text { Grease } \\
50 \%\end{array}$ & 28 & 26 & 26.5 & 27 & 27 \\
\hline $\begin{array}{l}\text { Grease } \\
75 \%\end{array}$ & 28 & 25.5 & 23 & 23.5 & 24.5 \\
\hline $\begin{array}{l}\text { Grease } \\
100 \%\end{array}$ & 24 & 25 & 22 & 24 & 24 \\
\hline
\end{tabular}

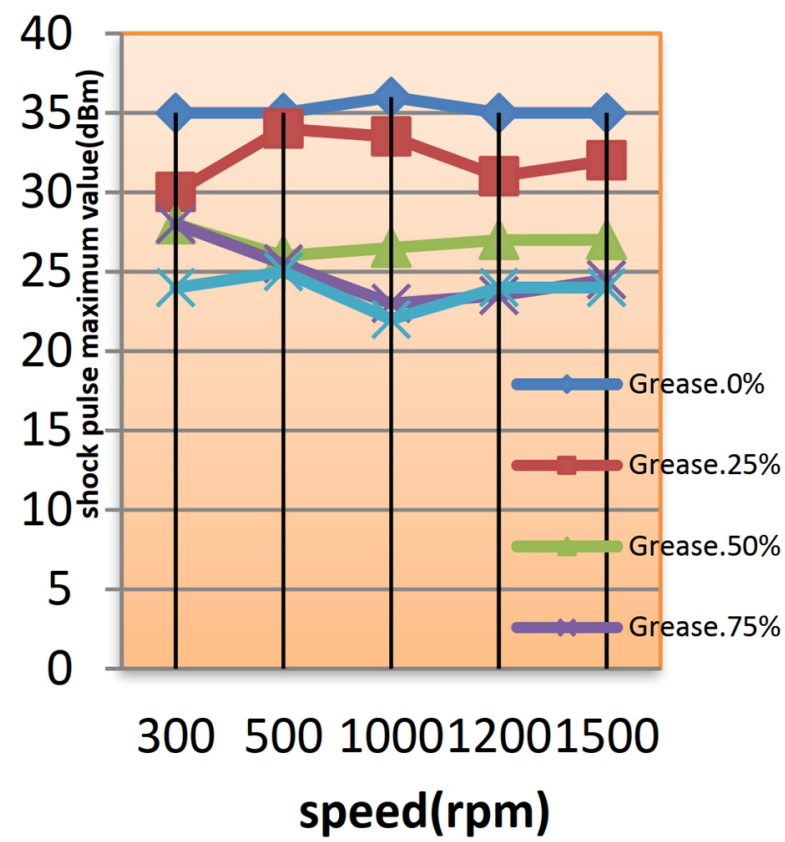

Fig. 11 Effect of qty of grease on shock pulse maximum $(\mathrm{dBm})$ and rpm.

Table 5 shows the shock pulse carpet values was taken at the speed of $1000 \mathrm{rpm}$ at different samples and plot the graph among these values. The value of $d B c$ was taken on the different $\%$ of grease with fixed speed $1000 \mathrm{rpm}$.

Table 5 .

\begin{tabular}{lccccc}
\hline $\begin{array}{l}\text { Lubricant } \\
\text { \%Applied(mg) }\end{array}$ & $0 \%$ & $25 \%$ & $50 \%$ & $75 \%$ & $100 \%$ \\
\hline $\mathrm{dBc}$ & 17 & 15.5 & 8 & 7.5 & 7 \\
\hline
\end{tabular}


shock pulse (dBc)graph at speed(1000rpm)

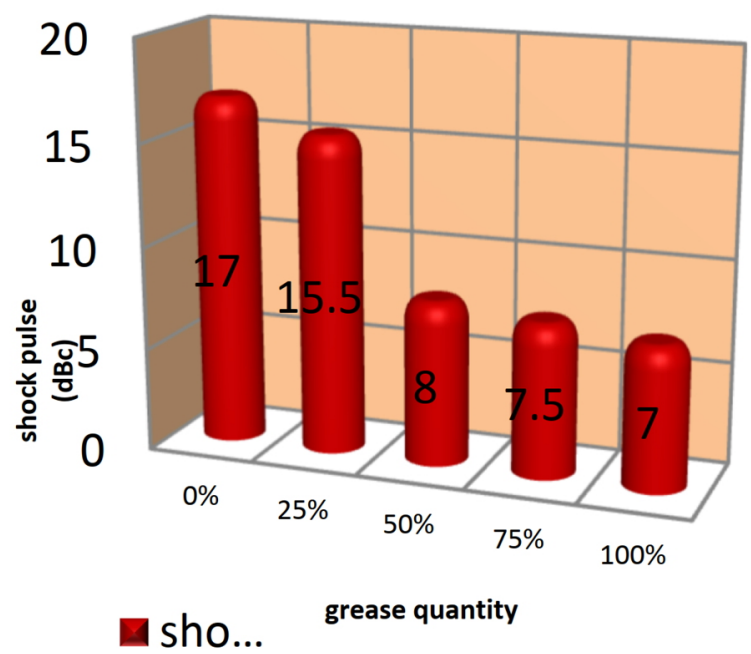

Fig. 12 graph between shock pulse $(\mathrm{dBc})$ and increasing \% of lubricant (grease) on $1000 \mathrm{rpm}$.

Table 6 shows the shock pulse maximum was taken at the speed of $1000 \mathrm{rpm}$ at different samples and plot the graph among these values. The value of $d B m$ was taken on the different $\%$ of grease with fixed speed $1000 \mathrm{rpm}$.

\section{Table 6.}

\begin{tabular}{cccccc}
\hline $\begin{array}{c}\text { Lubricant } \\
\text { \%Applied(mg) }\end{array}$ & $0 \%$ & $25 \%$ & $50 \%$ & $75 \%$ & $100 \%$ \\
\hline $\mathrm{dBm}$ & 36 & 33.5 & 26.5 & 23 & 22 \\
\hline
\end{tabular}

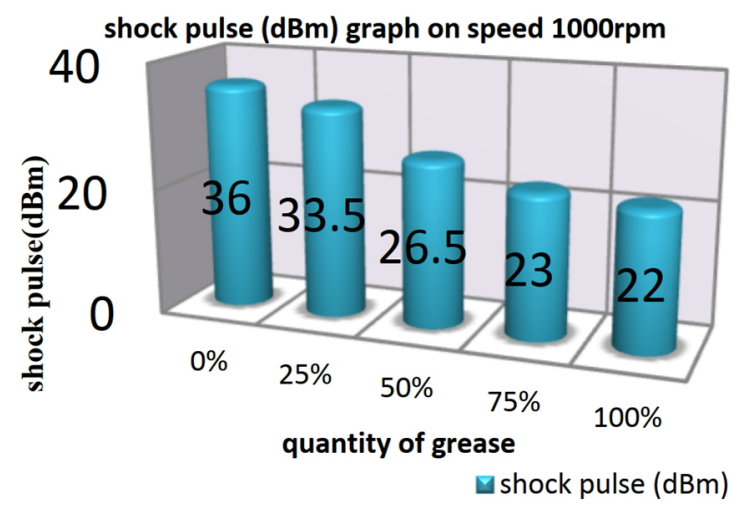

Fig. 13 graph between shock pulse $\mathrm{dBm}$ and increasing \% of lubricant (grease) on $1000 \mathrm{rpm}$.
The value of shock pulse $d B c$ and $d B m$ of heated grease (brunt) has been taken for $100 \%$ applied required grease in to the test bearing, at different rpm at fixed load $10 \mathrm{~kg}$.

Table 7

\begin{tabular}{cccccc}
\hline $\begin{array}{c}\text { Speed } \\
(\mathrm{rpm})\end{array}$ & 300 & 500 & 1000 & 1200 & 1500 \\
\hline$d B c$ & 23 & 24 & 23 & 23 & 21 \\
\hline$d B m$ & 34 & 36 & 34 & 35 & 26 \\
\hline
\end{tabular}

Figure 14-17 show the comparative graphs between fresh grease \& burnt grease on $100 \%$ lubricated condition with varying operative speed of $300,500,1000,1200,1500 \mathrm{rpm}$ on SPM parameter $d B c$.

\section{comprative graph of $\mathrm{dBc}$ of fresh \& heated grease}

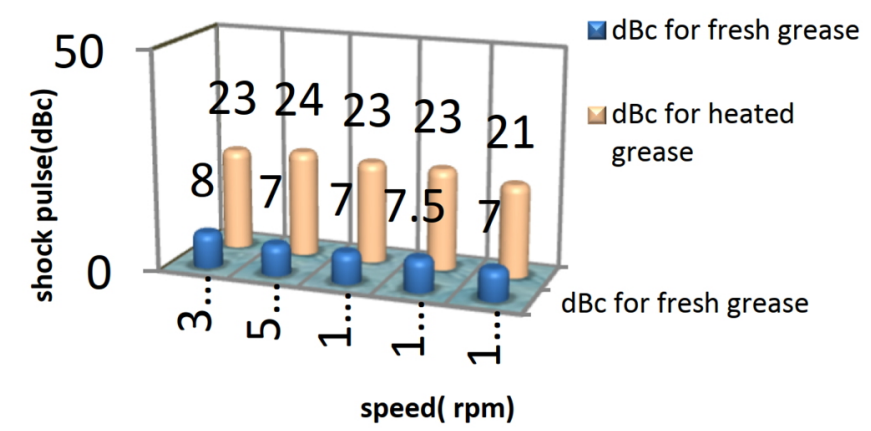

Fig. 14 comparative graph of $d B c$ between fresh \& heated grease.

Comparative graph between fresh grease \& heated grease on $100 \%$ lubricated condition with varying operative speed of $300,500,1000,1200,1500 \mathrm{rpm}$ on SPM parameter $\mathrm{dBm}$. 
comprative graph of $\mathrm{dBm}$ of fresh\& heated grease

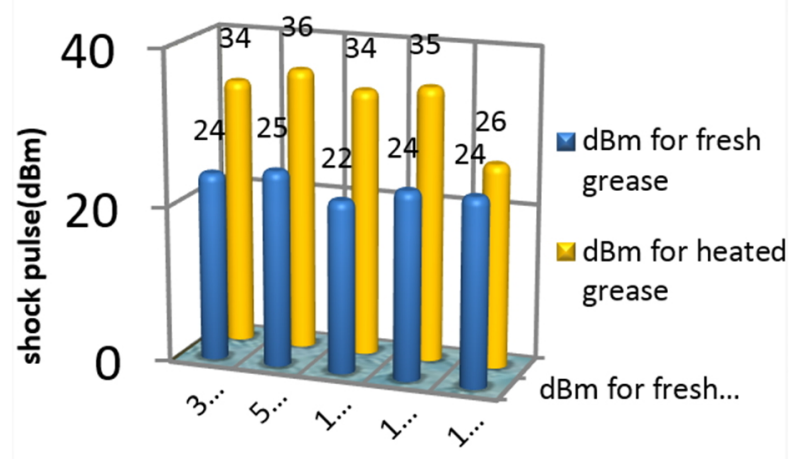

$\operatorname{speed}(\mathrm{rpm})$

Fig. 15 comparative graph of $\mathrm{dBm}$ between fresh $\&$ heated grease.

comparative chart of fresh grease \& heated grease on fixed speed(1000rpm)
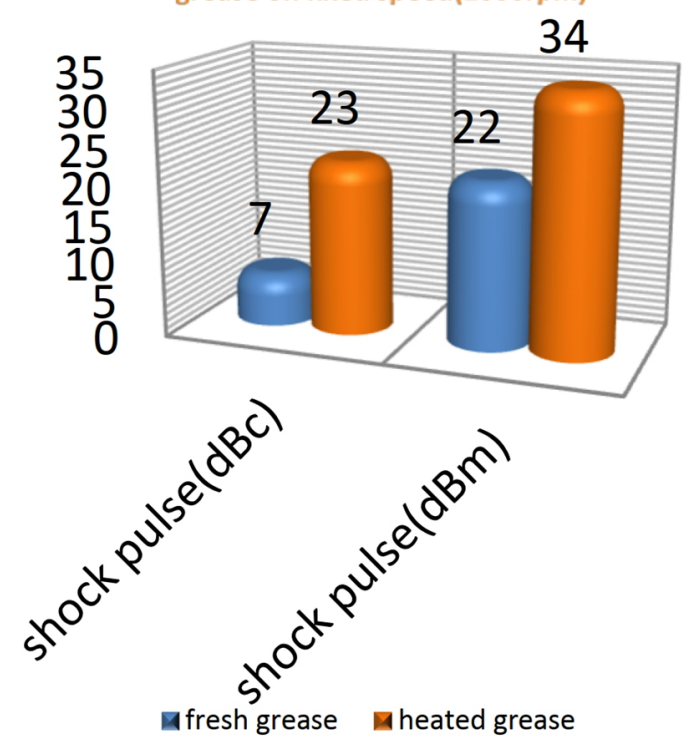

Fig. 16 comparative graph of $d B c \& d B m$ between fresh \& heated grease on 1000 rpm.

\section{RESULTS \& DISCUSSION}

With increasing the $\%$ of required quantity of grease from $0 \%-100 \%$ reducing the shock pulse carpet value $(d B c)$ from $19-7$ and shock pulse maximum value $(\mathrm{dBm})$ from $35-24$ at the $1500 \mathrm{rpm}$ at a fixed load $10 \mathrm{~kg}$ that mean if the bearing running without sufficient quantity of grease then the value of both shock pulse $(d B m \& d B c)$ getting more comparative graph and the value see Table 56 and Fig 10-11.

Type of grease and condition of grease also play important role, here we see the value of shock pulse carpet value $(d B c)$ from $7.5-$ 23 and shock pulse maximum value $(\mathrm{dBm})$ from $24-35$ at the $1000 \mathrm{rpm}$ at a fixed load $10 \mathrm{~kg}$ the value is min when we using fresh grease see Table 7 and graph Fig. 14-16.

So, we can say the shock pulse methods also play very important role for condition monitoring of grease quality.

\section{CONCLUSIONS}

From this research work, the following conclusions can be drawn -

1. It is found that when the bearing is running at $1000 \mathrm{rpm}$ speed and the quantity of applied grease is increased from $25 \%$ to $50 \%$, the value of $d B c$ changes from 15.8 to 8 ).

2. The value of $d B m$ changes from 33.5 to 26.5. After that the values of shock pulse $(d B c \& d B m)$ for the fresh grease applied $100 \%$ of total required amount and for the bad quality (burnt) grease ( $100 \%$ of total amount) at the speed of $1000 \mathrm{rpm}$ have been compared.

3. It is found that the values of $\mathrm{dBc}$ and $\mathrm{dBm}$, when the fresh grease was used, are 7 and 22 respectively. The values of $d B c$ and $d B m$ are 23 and 34 respectively, when the burnt grease is applied.

4. The shock pulse methods are effective for the detection of insufficient quantity of grease as well as the quality of grease .

\section{REFERENCES}

[1] Wikipedia

[2] N. Tandon, A. Choudhury, A review of the vibration and acoustic measurement methods for detection of defects in rolling element 
bearing, Tribol. Int. 32 (1999) 469-480.

https://doi.org/10.1016/S0301-

679X(99)00077-8

[3] D.E. Butler, The shock pulse method for the detection of damaged rolling bearing, NDT Int. 6 (1973) 92-95.

https://doi.org/10.1016/00291021(73)90116-3

[4] G.T. Zheng, W.J. Wang, A new cesptral analysis procedure of recovering excitations for transient components of vibration signals and applications to rotating machinery condition monitoring, J. Vib. Acoustics 123 (2001) 222-229.

https://doi.org/10.1115/1.1356696

[5] L. Li, L. Qu, Cyclic statistics in rolling bearing diagnosis, J. Sound Vib. 267 (2003) 253-265. https://doi.org/10.1016/S0022460X(02)01412-8

[6] J. Cheng, D. Yu, Y. Yang, A fault diagnosis approach for roller bearings based on EMD method and AR model, Mech. Syst. Signal Process. 20 (2006) 350-365. https://doi.org/10.1016/j.ymssp.2004.11.002

[7] N.G. Nikolaou, I.A. Antoniadis, Rolling element bearing fault diagnosis using wavelet packet, NDT E Int. 34 (2002) 197205. https://doi.org/10.1016/S0963$\underline{8695(01) 00044-5}$

[8] H. Jiang, Research on second generation wavelet construction theory and its applications in fault features extraction, Ph.D. Thesis, Xi'an Jiaotong university, China, 2006.

[9] Zhang R., Kang J., Hao L., Zhang X., Teng H., Li H., "Research on operating condition effect on Shock Pulse method", 5392-5398. DOI:10.11591/ijeecs.v12.i7.

[10] The shock pulse method for determining condition of anti-friction bearings, SPM Technical Information, Sweden, SPM Instruments $\mathrm{AB}$.

[11] Takeuchi k.et al. "Development of maintenance technology for rotation equipments in the takoi reprocessing plant 2 equipment diagnosis by using the SPM", Japan society of maintenology the $5^{\text {th }}$ science lecture meeting. 2008, 353-358.
[12] Miettinen, and Andersson, "Acoustic Emission of Rolling Bearings Lubricated With Contaminated Grease", Tribology International 33(11) (2000) 777-787. https://doi.org/10.1016/S0301679X(00)00124-9

[13] Tandon, and Choudhury, "A Review Of Vibration And Acoustic Measurement Methods For The Detection Of Defects In Rolling Element Bearings", Tribology International 32(8) (1999) 469-480. https://doi.org/10.1016/S0301679X(99)00077-8

[14] Tandon, "A comparison Of Some Vibration Parameters For The Condition Monitoring Of Rolling Element Bearings", measurement, 12 (1994) 285-289. https://doi.org/10.1016/02632241(94)90033-7

[15] Prashad, "Investigation Of Damaged Rolling Element Bearings And Deterioration Of Lubricants Under The Influence Of Electric Fields", Wear, 176 (1994) 151-161. https://doi.org/10.1016/00431648(94)90143-0

[16] Venner, et al., "Thin Layer Flow And Film Decay Modeling For Grease Lubricated Rolling Bearings", Tribology International 47 (2012) 175-187. https://doi.org/10.1016/j.triboint.2011.10.01 $\underline{9}$

[17] Onkar, et al. "Study Of Effect Of Solid Contaminants In The Lubricant On Ball Bearing Vibration", IJICA, 1(34) (2012) 2231-1890.

[18] Bob Kappa, "Predicting Bearing Failures And Measuring Lubrication Film Thickness In Your Plants Rotating Equipments", WEFTEC (2006) 5969- 5974. https://doi.org/10.2175/19386470678377566 $\underline{7}$

[19] Cousseau et al. "Film thickness in a ball ondisc contact lubricated with grease, bleed oil and base oils", Tribology International, 53 (2012) 53-60. https://doi.org/10.1016/j.triboint.2012.04.01 $\underline{8}$ 